\title{
Electrodelivery of Drugs into Cancer Cells in the Presence of Poloxamer 188
}

\author{
Iana Tsoneva, ${ }^{1}$ Iordan Iordanov, ${ }^{1}$ Annette J. Berger, ${ }^{2}$ Toma Tomov, ${ }^{1}$ Biliana Nikolova, ${ }^{1}$ \\ Nikola Mudrov, ${ }^{3}$ and Martin R. Berger ${ }^{2}$ \\ ${ }^{1}$ Institute of Biophysics, Bulgarian Academy of Sciences, Acad. G. Bonchev Street, Building 21, 1113 Sofia, Bulgaria \\ ${ }^{2}$ German Cancer Research Center, Toxicology and Chemotherapy Unit, Im Neuenheimer Feld 280, 69120 Heidelberg, Germany \\ ${ }^{3}$ Centre of Biomedical Engineering "Prof. Ivan Daskalov", Bulgarian Academy of Sciences, Acad. G. Bonchev Street, Building 103, \\ 1113 Sofia, Bulgaria
}

Correspondence should be addressed to Iana Tsoneva, itsoneva@obzor.bio21.bas.bg

Received 13 October 2009; Revised 7 April 2010; Accepted 10 June 2010

Academic Editor: Sonshin Takao

Copyright ( 2010 Iana Tsoneva et al. This is an open access article distributed under the Creative Commons Attribution License, which permits unrestricted use, distribution, and reproduction in any medium, provided the original work is properly cited.

In the present study it is shown that poloxamer 188, added before or immediately after an electrical pulse used for electroporation, decreases the number of dead cells and at the same time does not reduce the number of reversible electropores through which small molecules (cisplatin, bleomycin, or propidium iodide) can pass/diffuse. It was suggested that hydrophobic sections of poloxamer 188 molecules are incorporated into the edges of pores and that their hydrophilic parts act as brushy pore structures. The formation of brushy pores may reduce the expansion of pores and delay the irreversible electropermeability. Tumors were implanted subcutaneously in both flanks of nude mice using HeLa cells, transfected with genes for red fluorescent protein and luciferase. The volume of tumors stopped to grow after electrochemotherapy and the use of poloxamer 188 reduced the edema near the electrode and around the subcutaneously growing tumors.

\section{Introduction}

Cancer remains a leading cause of mortality despite the advances in its understanding, detection, and treatment. The use of high-voltage electrical pulses causes the formation of pores in cell membranes and thus increases the uptake of molecules like sugars, drugs, proteins, and DNA into cells [15].

The cell membranes are reversibly or irreversibly (necrosis, rupture) porated at given electrical parameters, as field strength and duration of pulses. The electroporation has been used to enhance the delivery of chemotherapeutic drugs like cisplatin and bleomycin in cancer cells and solid tumors, respectively. This application has been termed electrochemotherapy [6-9]. Its effectiveness is caused by increased uptake and accumulation of anticancer drugs into reversibly electroporated tumor cells. Side effects in terms of an acute inflammatory response have been thoroughly described after electrochemotherapy of animals tumors [10 19]. However, for the electrochemotherapy of human tumors the resulting secondary injury effects have not published in detail. Glass et al. [20] and Rebersek et al. [21] have shown that local side effects such as erythema and edema occurred at the treatment site after electrochemotherapy of human neoplasias and that these lesions disappeared within a period of 2-4 weeks. Peycheva et al. [8] have used a lower field strength for the electrotreatment of Mycosis fungoides to avoid possible skin necrosis or erythema when human lesions were in body regions with tender skin. The use of low field intensity to avoid side effects enforces and requires more than one electroprocedure [8].

For this reason experimental conditions have been sought, which would diminish the number or extent of such side effects. Poloxamer 188 (MW $8.4 \mathrm{kDa}$ ), poly(ethylene oxide)-poly(propylene oxide)-poly(ethylene oxide), is a water soluble triblock copolymer, a nonionic nontoxic surfactant, consisting of approximately 150 hydrophilic $(\sim 80 \%)$ and 30 hydrophobic monomers with a total length of $300 \AA$. The surfactant monomer is biologically active and has been used for different clinical and biological applications and could, for example, be a candidate to reduce the secondary injury effects $[22,23]$. 
To that end poloxamer 188 (P188) has been used to "seal" cells against the loss of carboxy-fluorescein dye after electroporation, to protect skeletal muscle cells after heat shock and against death due to loss of membrane integrity caused by neurotoxic effects [22-24]. Recently, P188 (which is $>80 \%$ polyethylene glycol (PEG)) has been described as a "free radical scavenger" $[25,26]$. Poloxamer 188 has been investigated by different physicochemical approaches on monolayer and bilayer membranes [27], but the mechanism of its action is not clear [28].

In the present study it is shown that poloxamer 188 added during or immediately after the electrical pulse used for electroporation reduces the number of dead cells and at the same time does not block the formation of reversible electropores through which small molecules such as anticancer drugs (cisplatin, bleomycin) or propidium iodide can pass/diffuse. The use of P188 did not block electrochemotherapy with cisplatin of tumors implanted into nude mice.

\section{Materials and Methods}

2.1. Chemicals. Poloxamer 188 named also Pluronik F68NF was from BASF Corporation (USA), Cisplatin from Medac, Germany, and Bleomycin from Euro Nippon Kayaku GMBH, Germany.

2.2. Cell Lines. The human breast adenocarcinoma cell line $M D A-M B-231$ was obtained from the American Type Cultural Collection (HTB-26) and grown as monolayer in RPMI-1640 medium supplemented with 10\% fetal calf serum (FCS) and $2 \mathrm{mM}$ L-glutamine. All cell lines were maintained at $37^{\circ} \mathrm{C}$ in an incubator with humidified atmosphere containing $5 \% \mathrm{CO}_{2}$ and were routinely passaged when $80-85 \%$ of cells were confluent using $0.25 \%$ trypsin and 0.02 EDTA (Invitrogen, Karlsruhe, Germany).

SKW-3 (DSMZ no. ACC 53, human chronic T-cell leukemia) and Jurkat cell lines (human acute T-cell leukemia) were also used. Both cell lines were grown as suspension cultures (RPMI-1640 medium, with 10\% FCS and $2 \mathrm{mM}$ L-glutamine) at the same conditions as described above. Cells were passaged two or three times per week to keep them in log phase.

Erythrocytes Venous blood erythrocytes from healthy donors were collected in a medium $(150 \mathrm{mM} \mathrm{NaCl}, 5 \mathrm{mM}$ EDTA, pH 7.4), then washed in $150 \mathrm{mM} \mathrm{NaCl}, 10 \mathrm{mM}$ TRIS$\mathrm{HCl}, \mathrm{pH} 7.4$, and for 3 times in $230 \mathrm{mM}$ sucrose, and finally resuspended in $230 \mathrm{mM}$ sucrose, $10 \mathrm{mM}$ TRIS-HCl, $\mathrm{pH}$ 7.4, at a concentration of $10^{9} \mathrm{cell} / \mathrm{s} / \mathrm{ml}$.

Nude Mice were obtained from Charles River (Sulzfeld, Germany) and maintained in a minibarrier system. They received food (Altromin) and autoclaved water. Two tumors were implanted subcutaneously in both flanks of the mice using a suspension $\left(10^{5}\right.$ cells $)$ of a HeLa cell subclone. These cells are stably transfected with plasmids for red fluorescent protein (RFP) and luciferase. Mice weighing about $25 \mathrm{~g}$ at an age of 6 to 8 weeks were used in the experiments. 30 tumors were used in total. Tumors grown to a size of $5-7 \mathrm{~mm}$ in diameter were used in the experiments. Visualisation of the tumors was done by an IVIS imaging system and given in $\mathrm{p} / \mathrm{sec} / \mathrm{cm}^{2} / \mathrm{sr}$ (the number of photons per second that leave a square centimeter of tissue and radiate into a solid angle of one steradian). DsRed is a red fluorescent protein (excitation wave length $500-550 \mathrm{~nm}$, emission wave length $575-650 \mathrm{~nm}$ ) and luciferase is an enzyme which cleaves the substrate luciferin. Before acquiring the luminescent image, a luciferin solution was injected into the animals intraperitoneally (i.p). Following cleavage, luciferin also emits photons which are then registered by the IVIS camera. In the case of luciferase/luciferin the images were taken maximally 10 minutes after i.p. injection of luciferin.

The tumor volume $\left(V_{0}\right)$ was calculated according to the formula $V_{0}=a x b^{2} / 2,(a \leq b)$, where $a$ and $b$ are the tumor length and width. The diameters of the lesions were measured by a caliper.

2.3. Electroporation Protocol. MDA-MB-231, Jurkat and SKW-3 cells ( $100 \mu \mathrm{l}$ with $5 \cdot 10^{5}$ cells) were electroporated in $0.3 \mathrm{M}$ mannitol, $0.1 \mathrm{mM} \mathrm{Ca}$ acetate and $0.1 \mathrm{mM} \mathrm{Mg}$ acetate. The sample chambers (Bio Rad Laboratories, Richmond, CA) were equipped with flat parallel electrodes, with electrode distance $d=0.4 \mathrm{~cm}$. The cell suspension was treated with one rectangular electrical pulse with $5 \mathrm{~ms}$ duration. The effective field strength $E_{0}=U_{0} / d\left(\mathrm{~V} \cdot \mathrm{cm}^{-1}\right)$, where $U_{0}$ is the electric voltage in $V$, was in the range of $1.0 \mathrm{kV} \cdot \mathrm{cm}^{-1}$. P188 at concentration $0.1,0.5$ or $1.0 \mathrm{mM}$ was added during or after the electroporation. After the electrical treatment, $900 \mu \mathrm{l}$ RPMI-1640, supplemented with 10\% FCS, was added to each sample. The controls were treated under the same conditions but without the application of an electrical pulse.

MTT Assay for Cells Survival (MTT Test). Cells were seeded in 96-well plates (flat tissue bottom, Becton Dickinson, Heidelberg, Germany) at a density of $5 \cdot 10^{4}$ cells per $100 \mu \mathrm{l} /$ well after the electroporation. The flat tissue bottoms were placed at $37^{\circ} \mathrm{C}$ in an incubator with humidified atmosphere and $5 \%$ $\mathrm{CO}_{2}$ for 24 hoursours (h). For each treatment, at least 8 wells were used. The cell viability fraction was determined by the MTT (3-(4,5-dimethylthiazol-2-yl)-2,5-diphenyltetrazolium bromide) dye-reduction assay, as described by Mosmann [29] with some modifications [30]. In brief, after the incubation period with the test compounds, MTT-solution (10 $\mathrm{mg} / \mathrm{ml}$ in PBS) was added $(10 \mu \mathrm{l} /$ well $)$. Plates were further incubated for 4 hours at $37^{\circ} \mathrm{C}$ and the formazan crystals formed were dissolved by adding $110 \mu \mathrm{l} /$ well acidified 2-propanol $(0.04 \mathrm{~N} \mathrm{HCl})$. Absorption was measured by an automated microtiter plate spectophotometer (Anthos, 2001) at $540 \mathrm{~nm}$, reference filter at $690 \mathrm{~nm}$. Complete medium $(100 \mu \mathrm{l})$, MTT stock $(10 \mu \mathrm{l})$ and $0.04 \mathrm{~N} \mathrm{HCl}$ in 2propanol $(110 \mu \mathrm{l})$ was used as photometric control.

Flow Cytometry Analysis (FACS)_Detection of Electropermeabilisation. Propidium iodide (PI), nonpermeate fluorescent dye, becomes detectable after entering into the permeabilised and/or damaged cells. FACS analysis was done immediately after every one treatment (less then 5 minutes). The PI was added in the suspension before or after the application 
of the electrical pulse at a final concentration of $100 \mu \mathrm{M}$. The percentage of permeabilised cells and mean fluorescence intensity were determined from the histogram obtained by flow cytometry (FACS Calibur, Becton Dickinson, USA) according to the protocol given by Pucihar et al. [31]. On the histogram of the electrotreated probe, the position of the two markers (M1 and M2) was selected at the apparent boundary between the population of nonpermeabilised (M1) and permeabilised cells (M2). The position of the markers was kept the same for all investigated parameters in the frame of one experiment. Intact cells of the control sample were approximately $80-95 \%$. The number of counted cells was not less than 20000 per sample.

Electrohaemolysis. Haemolysis was done according to Tomov [32] with modification. An erythrocytes' suspension $(0.3 \mathrm{ml})$ was poured into a BioRad cuvette with flat $\mathrm{Al}$ electrodes, distance $0.2 \mathrm{~cm}$. Electrohaemolysis was obtained by the application of one rectangular pulse of $3 \mathrm{kV} \cdot \mathrm{cm}^{-1}$ with a duration of $0.5 \mathrm{~ms}$. The chamber was washed three times with medium (230 mM sucrose, $10 \mathrm{mM}$ TRIS- $\mathrm{HCl}$, pH 7.4) and then the total erythrocytes' suspensions were incubated on ice for a given time (1-5 hours) and then centrifuged. The collected supernatant was analyzed spectrophotometrically at $540 \mathrm{~nm}$. The extent of erythrocyte lysis was defined as a ratio (in percent) between the extinction of electroporated erythrocytes and that of erythrocytes haemolysed by distillated water (100\% lysis).

Electrochemotherapy of Tumors. The animal studies were approved by the responsible authority for animal experiments (Regierungspraesidium Karlsruhe). In case of chemotherapy $150 \mu \mathrm{l}(0.5 \mathrm{mg} / \mathrm{ml})$ cisplatin were injected intraperitoneally (i.p.) two times during the first week of treatment. Electrochemotherapy predominantly is a singleact procedure which was carried out as follows: First $50 \mu \mathrm{l}$ of $1 \%$ lidocaine was injected into the tumor and, using the same needle, $50 \mu \mathrm{l}(0.5 \mathrm{mg} / \mathrm{ml})$ cisplatin was administered into the tumor 5 minutes later. Then electrical pulses were applied five minutes after the injection of cisplatin. P188 in $0.5 \mathrm{ml}$ RPMI medium (at $0.1 \mathrm{mM}$ concentration) was injected i.p. 5 min after electrochemotherapy. The concentration of P188 was based on the assumption that the extracellular fluid volume equals about $24 \%$ of the total body weight [33].

For tumor electrochemotherapy a new electroporator generating biphasic pulses had been developed because these are more efficient and better tolerable to the patients. The instrument is equipped with a large voltage control in the limits of 100-2200 V, simplified operations, locking against illegal manipulations, a battery supply, enhanced protection against electrical hazards both for the patient and the physician, autonomy providing for more than 200 electroporations with one battery charge, and a recharging time for a depleted battery of less than 10 hours. The weight of the apparatus is about $3 \mathrm{~kg}$. The electrochemotherapy with cisplatin was carried out with series of 8 biphasic pulses, each of them with $50 \mu s+50 \mu$ s duration and pause of one ms between them, thus the total duration of the series reached $7.8 \mathrm{~ms}$. The use of biphasic electrical pulse sequence was introduced for electrochemotherapy, because this procedure resulted in improved efficiency and tolerability by the patients (as determined by the reduction of muscle's contractions) [34]. Optimal contact with skin was ensured with the aid of an electroconductive gel. The field strength for electrochemotherapy was $1200 \mathrm{~V} \cdot \mathrm{cm}^{-1}$. The electrodes were a pair of parallel stainless steel wires of $0.8 \mathrm{~mm}$ in diameter and $15 \mathrm{~mm}$ of length. The interelectrode distance was adjustable (caliper type) in the range of 5-30 mm.

\section{Results}

3.1. Viability of Cells by MTT Test. Viability of MDA-MB231 cells was checked by MTT test (cytotoxic or therapy test), which gave the percentage of irreversibly porated cells after the application of one rectangular electrical pulse with $5 \mathrm{~ms}$ duration and $1 \mathrm{kV} \cdot \mathrm{cm}^{-1}$ field intensity with or without treatment (Figure 1). MTT was added 24 hours after the treatment. Experiments connected with MTT test were carried out to find the best conditions for the electrodelivery of anticancer drugs into the cells. We sought to establish conditions following which the electroloading of cells with drugs would be carried out in cells which in their majority were not irreversibly damaged. In this case, the electrical parameters were such that the irreversibly porated cells amounted to $20-25 \%$ of total cells. Poloxamer 188 was added before or immediately after the electrical pulse application. The number of surviving cells increased by $15 \%$ up to $90 \%$ compared with the electroporated control, if P188 was present during the pulse. The use of poloxamer 188 at the same concentration but added after the pulse increased the number of surviving cells by additional $4 \%$ up to near $95 \%$. The share of destructed cells (probably dead by apoptosis) following exposure to $10 \mu \mathrm{M}$ cisplatin (without pulse) was $26 \%$ and after additional electroporation increased by two times. Additional exposure to P188 increased the share of dead cells to about $65 \%$, regardless whether electroporation was done before or after adding P188.

Bleomycin is an antibiotic that does not pass through the intact membrane by passive diffusion. The cytotoxic effect of bleomycin administered together with a pulse was $60 \%$ and reached even 70\% in the presence of P188 (added before or after the pulse).

From the data given in Figure 1 it is obvious that poloxamer 188 does not block electroloading of cells with anticancer drugs as cisplatin or bleomycin. On the contrary, the presence of this polymer during the pulse or added after the electrotreatment increased the number of dead cells in response to the two cytotoxic agents. Similar results were obtained by MTT test with SKW-3 and Jurkat cells following application of one pulse of $5 \mathrm{~ms}$ duration and $1.0 \mathrm{kV} \cdot \mathrm{cm}^{-1}$ field strength (data not shown).

3.2. Electropermeabilisation with Propidium Iodide and FACS Analysis. The electropermeabilisation was followed by flow cytometry measurements with PI [31]. The dye was added 


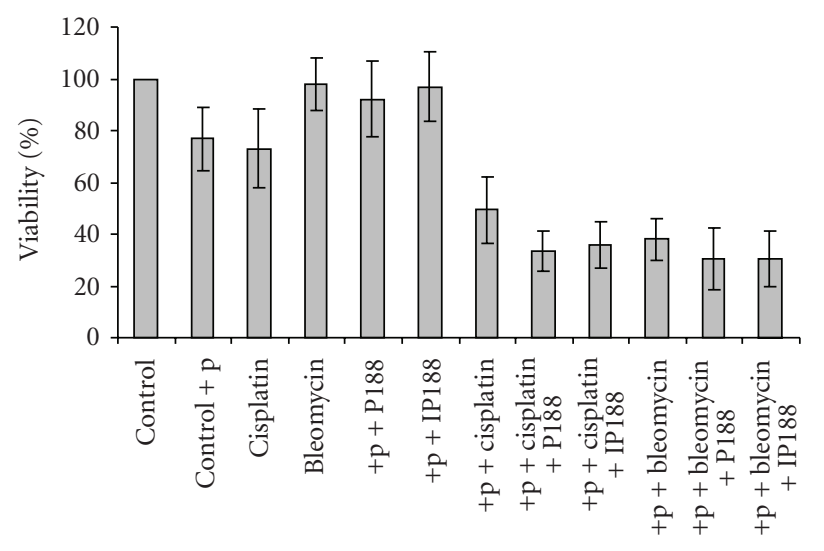

FIGURE 1: MTT test of treated MDA-MB-231 cells at 24 hoursours after treatment; $5 \cdot 10^{5}$ cells suspended in $100 \mu \mathrm{l}$ of a buffer $(0.3 \mathrm{M}$ mannitol, $0.1 \mathrm{mM} \mathrm{Ca}$ acetate and $0.1 \mathrm{mM} \mathrm{Mg}$ acetate) were electroporated according to the following electrical parameters: field strength $1.0 \mathrm{kV} \cdot \mathrm{cm}^{-1}$ and one rectangular pulse with a duration of $5 \mathrm{~ms}$. Cisplatin was used at $10 \mu \mathrm{M}$ and bleomycin-at $20 \mu \mathrm{M}$ concentration. $+\mathrm{p}$ indicates electroporated probes, $+\mathrm{P} 188$ indicates that cells were electroporated in the presence of $0.1 \mathrm{mM}$ $\mathrm{P} 188$, and $+\mid \mathrm{P} 188(0.1 \mathrm{mM})$ indicates the addition of P188 after the electrical pulse. All probes were diluted under identical conditions. The data represent the mean values from three experiments.

at $100 \mu \mathrm{M}$ concentration to the cell suspension containing $5 \cdot 10^{5}$ cells $\left(12 \cdot 10^{9}\right.$ PI molecules per cell). The fraction of electropermeabilised cells is the percentage within the M2 marker (Figures 2-4).

The electropermeabilisation state of MDA-MD-231 cells is shown in Figure 2. The nonpermeable cells of the control (non treated cells) in the M1 fraction (Figure 2(a)) were approximately $80 \%$ and in the M2 fraction were $20 \%$. Cells in M2 in the electroporated control were 93\% (Figure 2(b)). A similar number of permeable cells in M2 was found (Figures 3(d), 3(f) and 3(h)), when the electropermeabilisation was done in the presence of P188 $(0.1,0.5$ and $1.0 \mathrm{mM})$. The number of permeable cells in M2 is nearly equal in all probes containing poloxamer 188 , ranging from 0.1 to $1.0 \mathrm{mM}$ $\left(12 \cdot 10^{9}-12 \cdot 10^{10}\right.$ molecules per cell).

In the case when PI was added within one minute after the pulse, the cells in M2 were reduced by $4 \%$ (Figure 2(c)). The mean value of electropermeability was about $90 \%$ and it was reduced by $3-7 \%$ as compared with the samples where PI was present during the pulse. Practically, the permeability of the cells for PI was not considerably changed when P188 was added before or after the pulse (Figures 2(d)-2(i)).

The flow cytophotometric behavior of the two other types of cells (SKW-3 and Jurkat) is shown on Figures 3 and 4. The data about the permeabilisation state in all variants of treatment are similar to these given in Figure 2.

The data from experiments carried out by FACS analysis (Figures 2-4) show that P188 added during or after the pulse did not block the formation of small electropores through which small molecules are able to pass, like PI, or cisplatin and bleomycin, respectively. The effects were not dependent on the concentration of P188 (Figures 2-4).
3.3. Electrohaemolysis. The kinetics of haemolysis after application of one rectangular pulse of $3 \mathrm{kV} \cdot \mathrm{cm}^{-1}$ (duration of $0.5 \mathrm{~ms}$ ) in the presence of a very low concentration of P188 $(10 \mu \mathrm{M})$ is shown in Figure 5. Each point reflects the ratio between electroporated erythrocytes (erythrocytes alone, in the presence of P188 or P188 is added after electroporation) and erythrocytes haemolysed by distillated water (100\% lysis). The percentage of erythrocytes haemolysed within one hour was $40 \%$ and reached $95 \%$ after 5 hours. When electroporation was done in the presence of P188, haemolysis after one hour was $22 \%$ and after 5 hours $60 \%$, while when P188 was added after the electrotreatment the extent of haemolysis was 38\% after one hour and reached a plateau of about $60 \%$ after 2 hours. The protective effect of P188 was less clear if the compound was added after electroporation, however after 5 hours the extent of haemolysis was $60 \%$ for both exposure modalities (Figure 5).

The dependence of electrohaemolysis on the concentrations of P188 after 3 hours is given in Figure 6. Experimental conditions for the electroporation (field strength of $3 \mathrm{kV}$. $\mathrm{cm}^{-1}$ and 1 pulse with a duration of $0.5 \mathrm{~ms}$ ) were such that the extent of the irreversibly damaged erythrocytes was high. The number of electrohaemolysed (irreversibly electroporated) cells was reduced with the increase in the concentration of P188.

3.4. Electrochemotherapy of Xenografts. The changes in tumor growth after the various treatment arms are shown in Figure 7. Chemotherapy with cisplatin reduced the tumor volume by $50 \%$ compared with untreated controls (not significant). The electrotreatment modes (electrochemotherapy or electrochemotherapy + P188) stopped the tumor growth within the observation period of 30 days. This corresponds to a tumor growth inhibition of more than $90 \%$ compared to untreated controls and is highly significant. The differences in tumor growth were analysed by the Kruskal Wallis test and found significant for the two electroporation groups.

Figure 8 shows the pictures of two representative cases of tumors: Untreated control (mouse to the right) and after electrochemotherapy with cisplatin and concomitantly i.p. intraperitonially injected P188 (mouse to the left). In our case there are small differences in using DsRed (red fluorescent protein) and luciferase signals. Luciferase detection gave a stronger signal, permitting the detection of small tumors, whereas Ds Red was preferable in the case of big tumors, because with big tumors, the strong luciferase signals might overlap.

According to WHO (World Health Organisation) guidelines the treatment response has to be evaluated at least 4 weeks after the therapy and a complete response is achieved only in the absence of any trace of tumor at that time. The tumors stopped to grow but were not in complete response within the frame of the observation period of one month. Some edema was observed around the tumors in response to electrochemotherapy. The use of P188 reduced the skin edema near the electrode and around the subcutaneously growing tumors, which occurred during the first days after treatment. 


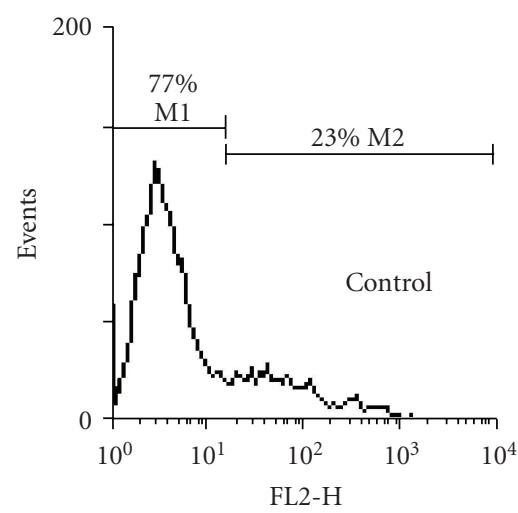

(a)

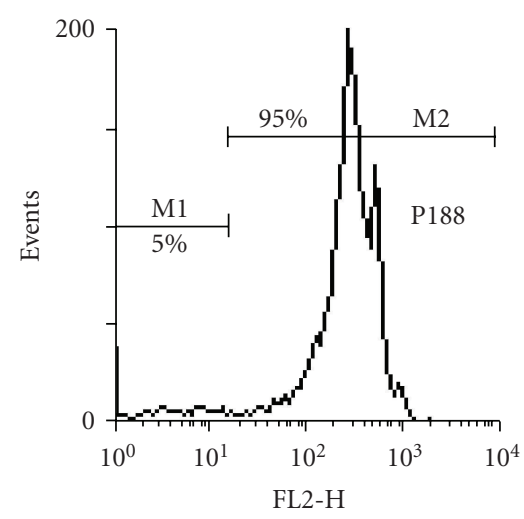

(d)

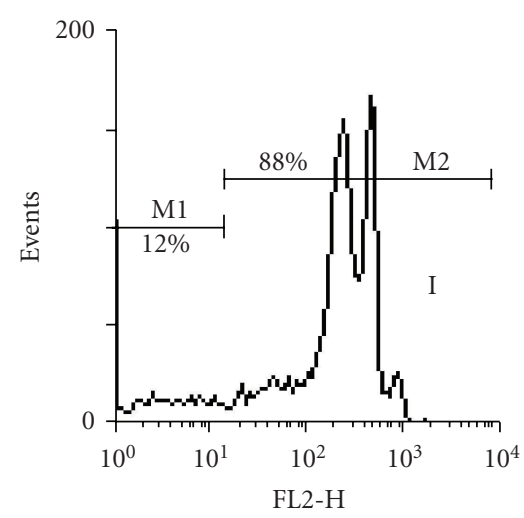

(g)

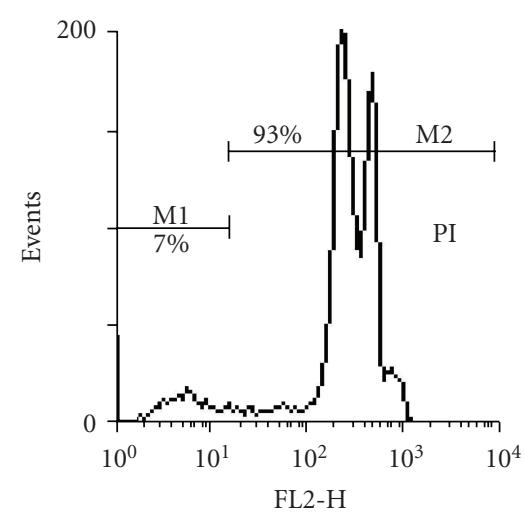

(b)

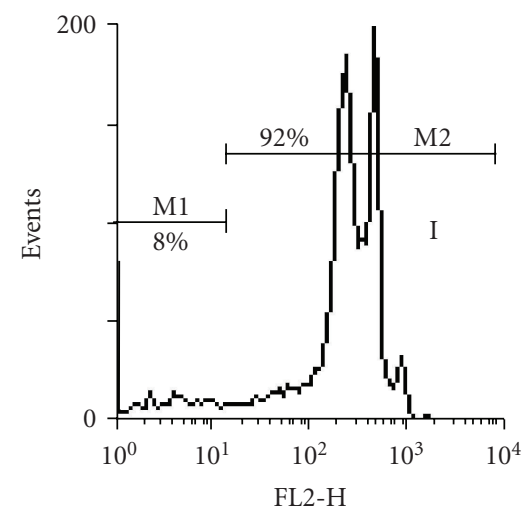

(e)

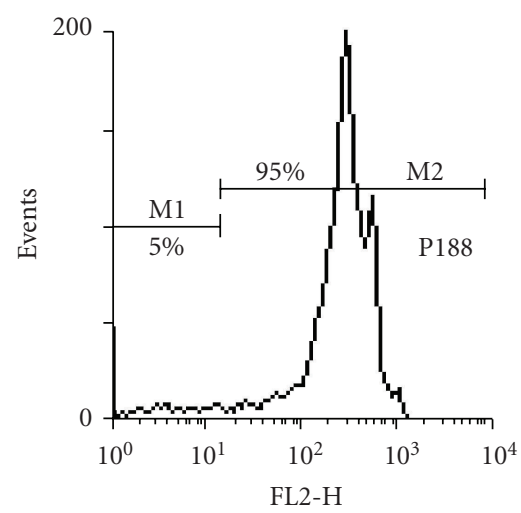

(h)

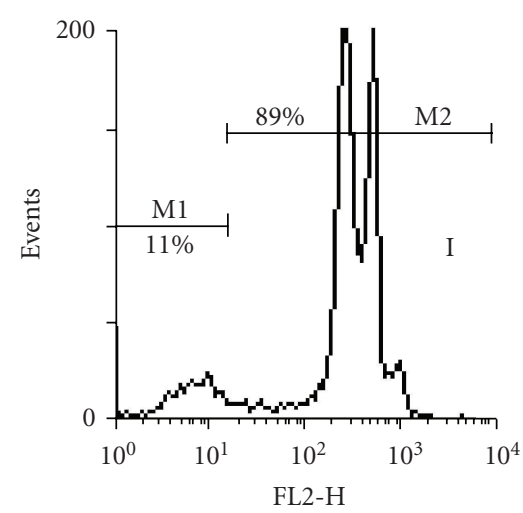

(c)

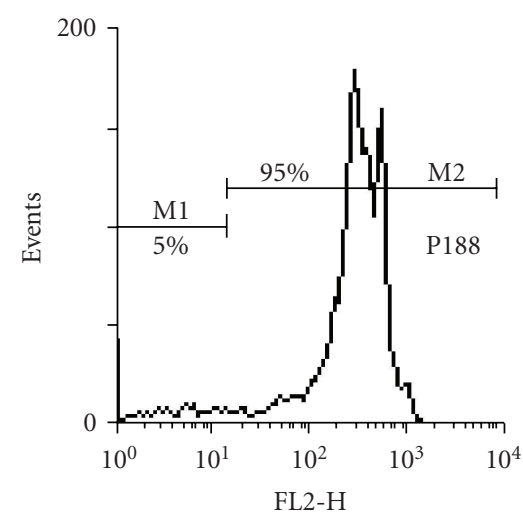

(f)

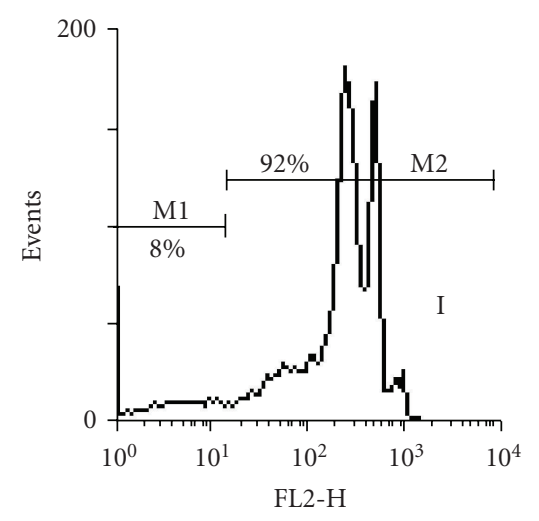

(i)

Figure 2: Flow cytometry of MDA-MB-231 cells. Experimental conditions: $5 \cdot 10^{5}$ cells per $100 \mu \mathrm{l}$ suspension of $0.3 \mathrm{M}$ mannitol, $0.1 \mathrm{mM}$ Ca acetate and $0.1 \mathrm{mM} \mathrm{Mg}$ acetate. Field strength $-1.0 \mathrm{kV} \cdot \mathrm{cm}^{-1}$, one pulse with a duration of $5 \mathrm{~ms} .100 \mu \mathrm{M}$ propidium iodide (PI) was added during the pulse or after it; (a) nonporated control with PI added; (b) porated control with PI added before the pulse; (c) porated control with PI added after the pulse; (d) and (e) $0.1 \mathrm{mM}$, (f) and (g) $0.5 \mathrm{mM}$, (h) and (i) $1.0 \mathrm{mM}$ poloxamer 188 and $100 \mu \mathrm{M}$ PI added; (d), (f) and (h) are samples electroporated in the presence of poloxamer 188 and PI; (e), (g) and (i) poloxamer 188 and PI were added after the pulse. The M1-marker represents the nonpermeable cells and the M2-marker-the permeable cells.

\section{Discussion}

Up to date the copolymer P188 has been used for various biological and medical purposes [22-25]. The critical micelle concentration (CMC) for poloxamer 188 is $100 \mathrm{mg} / \mathrm{ml}$ according to Kabanov et al. [35] and $12.5-51.7 \mathrm{mg} / \mathrm{ml}$ according to Alexandridis and Hatton [36]. In our experiments $\mathrm{P} 188$ was used at concentrations ranging from 0.01 to $1.0 \mathrm{mM}(0.084-8.4 \mathrm{mg} / \mathrm{ml})$. For in vitro membrane applications, P188 is typically used at concentrations below its CMC 


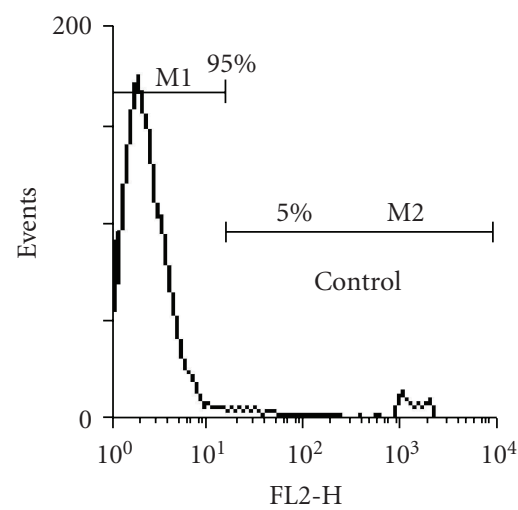

(a)

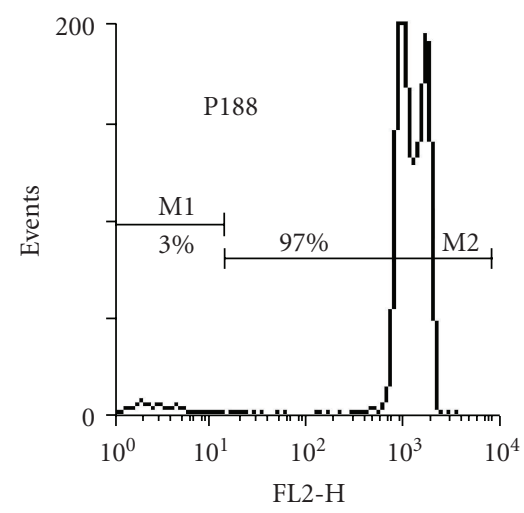

(d)

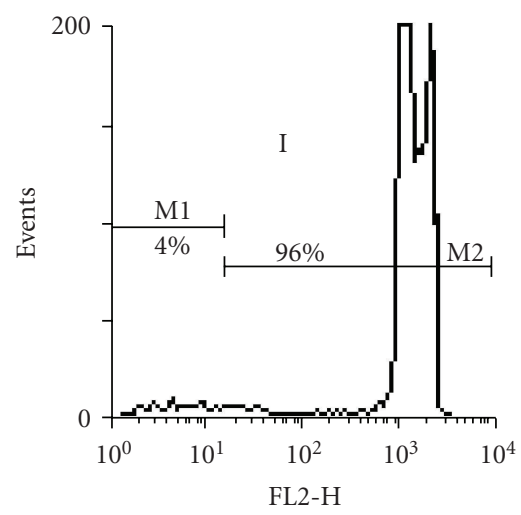

(g)

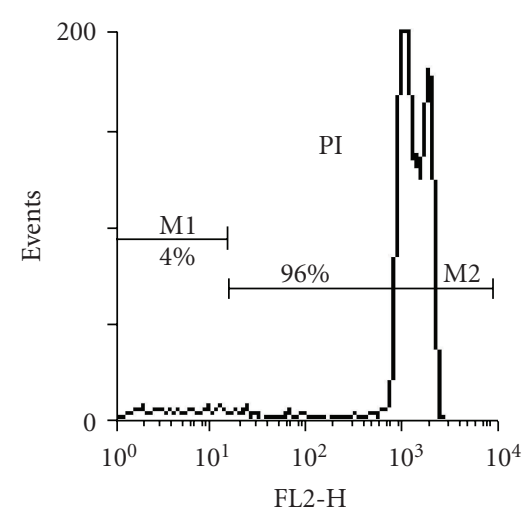

(b)

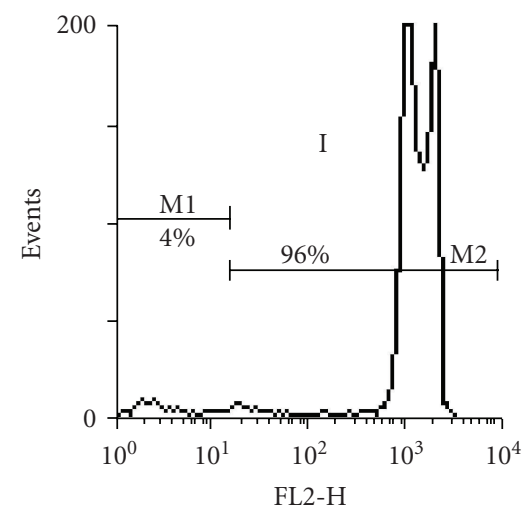

(e)

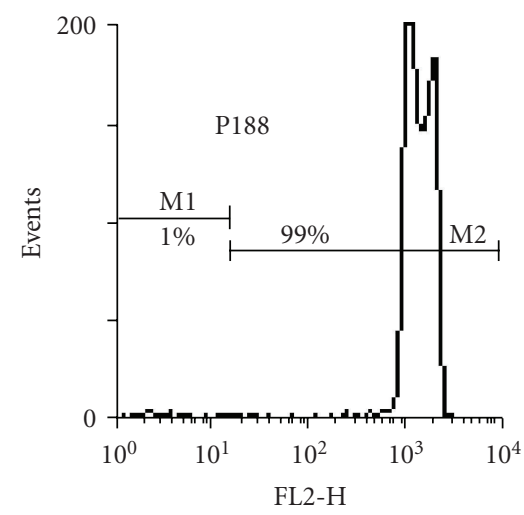

(h)

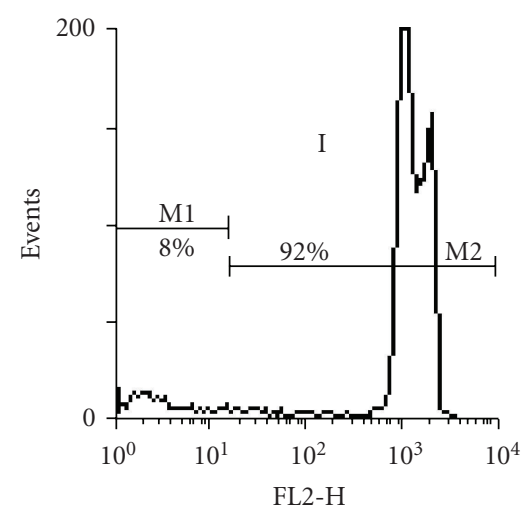

(c)

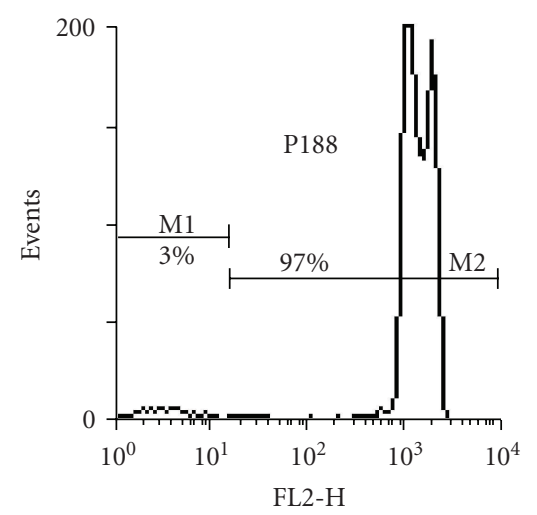

(f)

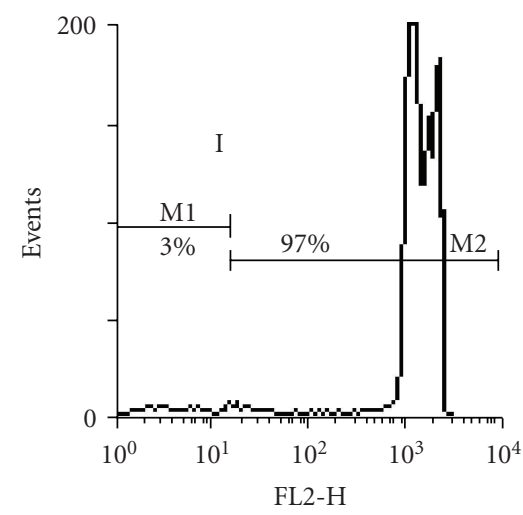

(i)

FIGURE 3: Flow cytometry of SKW-3 cells. Other conditions are the same as in Figure 2.

[28]. We suppose that poloxamer 188 at the concentrations used by us is in monomer form that corresponds to its biologically active form.

The results in Figures 1-4 show that this copolymer did not block the entrance of anticancer drugs with small sizes from 300 to $1400 \mathrm{Da}$ as cisplatin or bleomycin, as well as of propidium iodide if P188 was added during the pulse or immediately after it.

Flow cytometry showed that the PI permeability is not dependent on the increase in the concentration of P188 (Figures 2-4). The mean number of electropores per cell is expected to be about $2.4 \cdot 10^{4}$ [5]. Liu-Snyder et al. [26] have shown that fluorescently decorated PEG binds to the membrane surface of the cells but does not enter the cytoplasm. We also suggest that the P188 molecules are concentrated in the area near the cell surface. We suppose that some molecules of P188 are inserted in the pore and some are free in the suspension.

For the first time Lee et al. [24] used the triblock poloxamer 188 to "seal" cells after electroporation in the frame of 30 minutes. We followed the kinetic of haemolysis after the electrotreatment (1-5 hours). After 5 hours the 


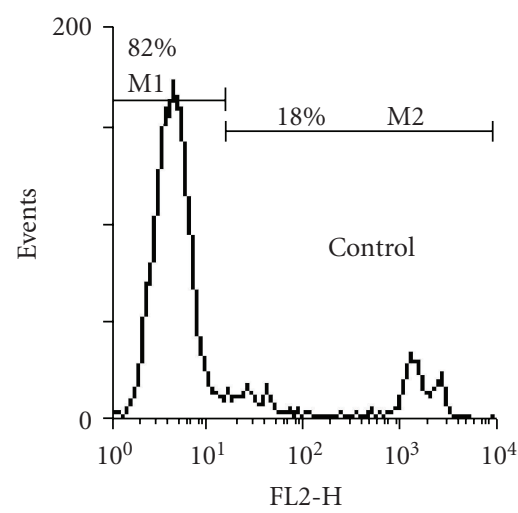

(a)

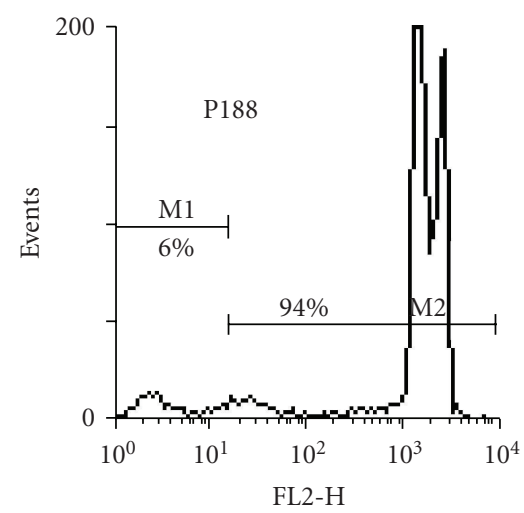

(d)

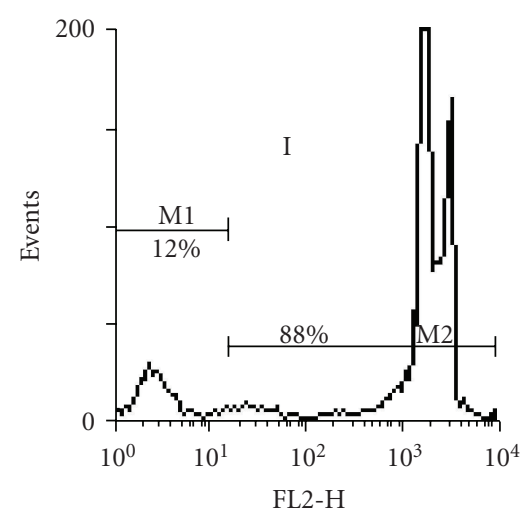

(g)

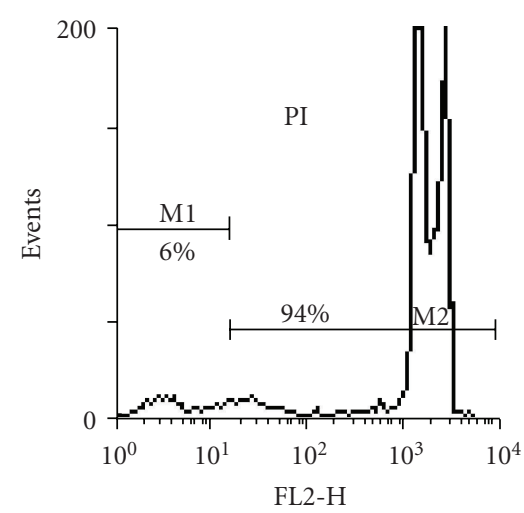

(b)

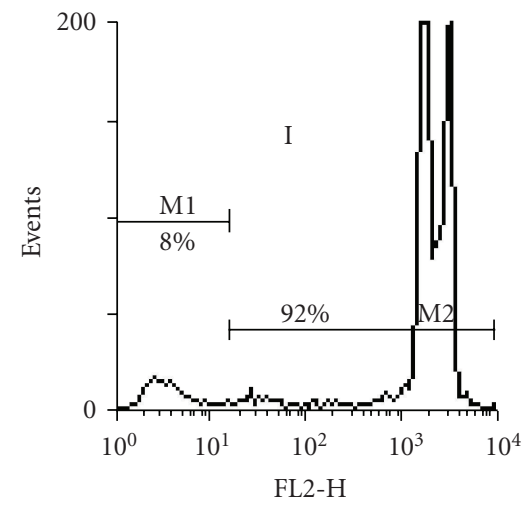

(e)

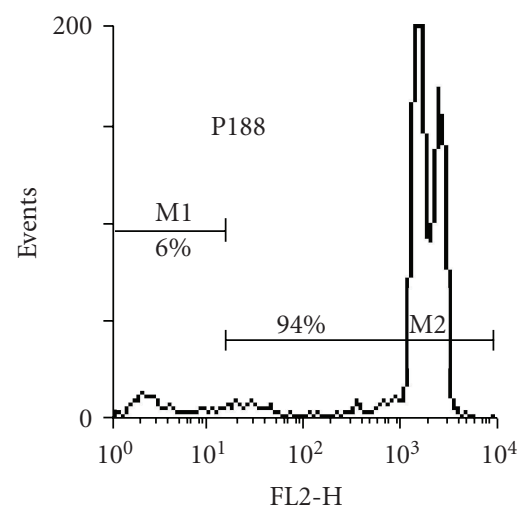

(h)

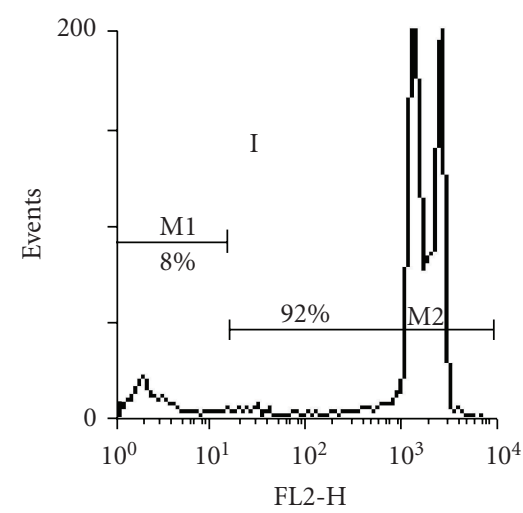

(c)

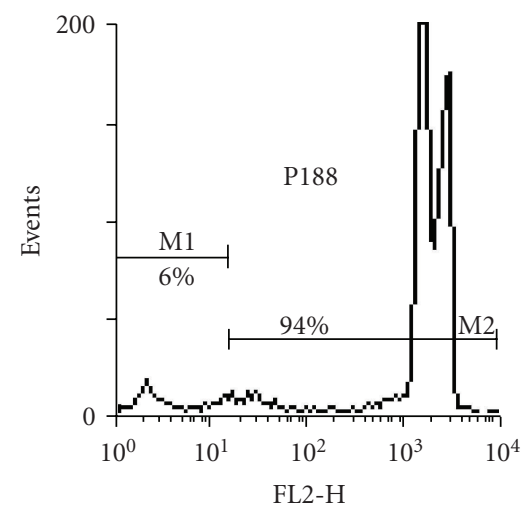

(f)

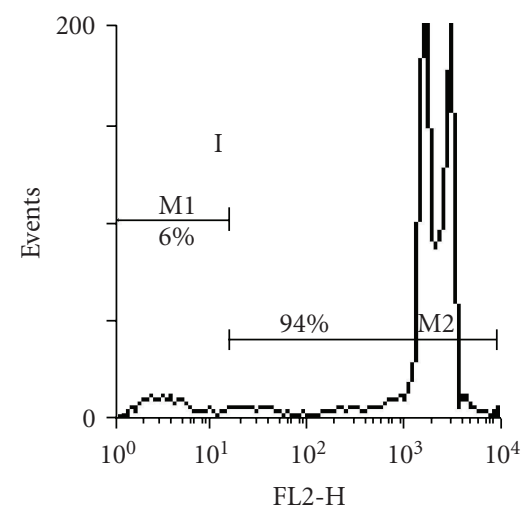

(i)

FIgURE 4: Flow cytometry of Jurkat cells. Other conditions are the same as in Figure 2.

number of irreversibly destroyed erythrocytes was equal (Figure 4) but if P188 was added immediately after the pulse the final value was reached earlier (after 2 hours).

Photos et al. [37] have demonstrated that polymersome vesicles, made from diblock copolymers of poly(ethylene oxide-polybutadiene (PEG-PBD)) possess long-lasting small pores after electroporation treatment. By using a modified version of electroporation, the authors [37] inspired comparisons of brushy pores observed by them with the structure of the nuclear pore complex, which selectively regulates the transport of some proteins or molecules into the cell nucleus by binding to the brush and decreasing the entropy. We have observed some increase in viability if poration was done in the presence of P188 (Figure 1). The diffusion of cisplatin, bleomycin or PI into the cells was not blocked by the used triblock polymer. We therefore suggest that P188 forms so called "brushy pores", similar to the diblock polymer [37], that permit some small molecules to pass through the pores or block the leakage of ions which are essential for cell survival. 


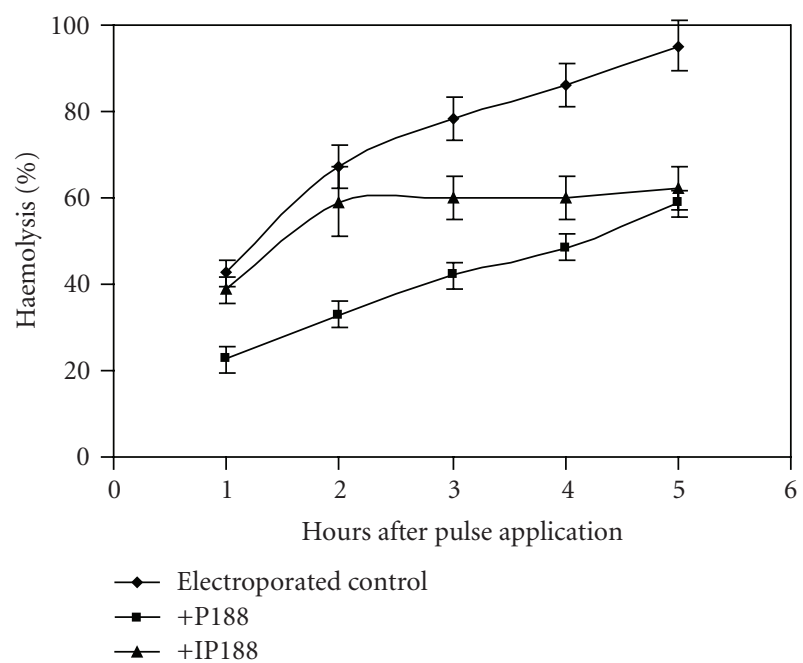

FIGURE 5: Altered haemolysis after the application of one rectangular pulse of $3 \mathrm{kV} \cdot \mathrm{cm}^{-1}$ and duration $0.5 \mathrm{~ms}$ in the presence of $10 \mu \mathrm{M}$ poloxamer 188 . $+\mathrm{P} 188$ indicates that erythrocytes were electroporated in the presence of $10 \mu \mathrm{M} \mathrm{P} 188$, and $+\mid \mathrm{P} 188(10 \mu \mathrm{M})$ indicates the addition of P188 after the electrical pulse.

On the basis of the experimental results (Figures 1-5) we suggest the following mechanism of action of triblock copolymer (Figure 9).

Poloxamer 188 consists of a $1750 \mathrm{Da}$ average molecular weight hydrophobic part (30 propylene oxide units) and a 6 650 Da hydrophilic part $(2 \times 76$ ethylene oxide units—about $80 \%$ of the total molecular weight). In monomer form the total length of P188 is about $300 \AA$. The hydrophobic section of P188 could be inserted into the hydrophobic part of the pore edges or into some defect part of an electroporated membrane. Its free hydrophilic parts could act as a flexible brush in the hydrophilic pore allowing the diffusion of small molecules into the cells. Due to the small hydrophobic part of P 188 as compared with some membrane molecules such as cholesterol showing a bigger size and more intense hydrophobic interactions, this copolymer is eliminated from pores and the membrane within $2-5$ hours. Our data show that the irreversible permeabilisation is in deed reduced (Figures 1, 5, 6). The formation of brushy pores may reduce the expansion of pores and delay the irreversible electroporation. The reversible electropores, decorated with P188 could be in long-lived state also. We have found some differences in the kinetics of electrohaemolysis when the electroporation was done in the presence of P188 (Figure 5). A reduction of the colloid-osmotic lysis (the irreversible electroporation) is less probable which could occur due to the blocking of the osmotic pressure of big-molecular weight components of the cytoplasm in the presence of big molecules of this copolymer in the medium. The concentration of haemoglobin in one erythrocyte is $5 \mathrm{mM}$. The concentration of P188 (0.1-1.0 mM) was very low compared with the concentration of huge molecules such as haemoglobin in erythrocytes or proteins in general within other cell types. The data in Figure 6 show the dependence

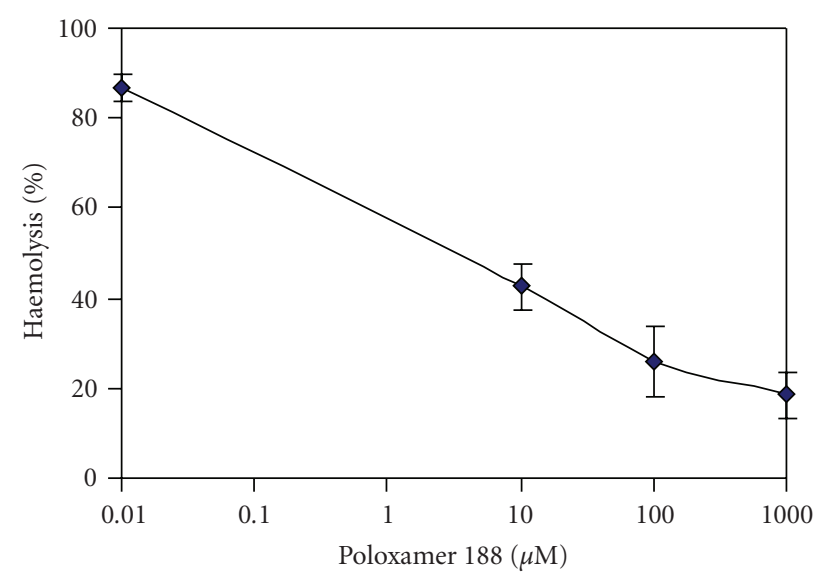

Figure 6: Haemolysis of erythrocytes, electroporated in the presence of different concentrations $(\mu \mathrm{M})$ of P188 after 3 hours. The electrical parameters were the same as in Figure 5. The abscissa is in logarithmic scale, the point 0.01 corresponds to the control (zero concentration of P188).

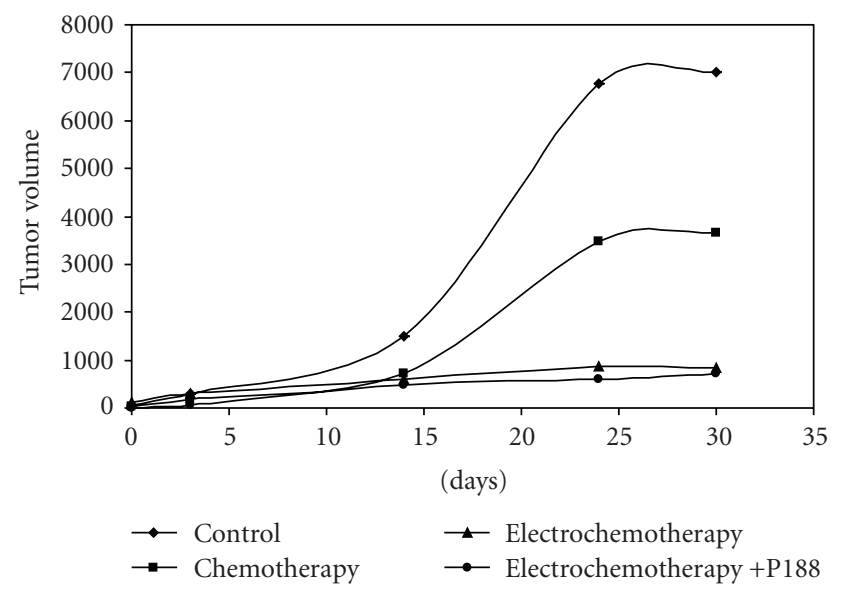

Figure 7: Growth curves of HeLa tumors implanted in Nude mice: control (without any treatment); chemotherapy with cisplatin; electrochemotherapy with cisplatin injected intratumorally, electrochemotherapy in the presence of P188 injected 5 minutes after pulses intraperitoneally. The observed time was 30 days. Points are mean value of three tumors. Standard errors are omitted due to the overlap of the bars.

of electrohaemolysis (irreversible electroporation) on the concentration of P188. This could suggest that some big molecules that are not inserted in pores protect cells from lysis or rupture by their adsorption onto the cell surface, thus increasing the cellular membrane stability additionally.

The edema after electrochemotherapy was reduced. It is known that P188 can decrease the inflammation after electropermeabilisation and different mechanical tissue injuries by recruiting neutrophils and macrophages into damaged areas $[33,38]$. In the present study (in vivo and in vitro) 


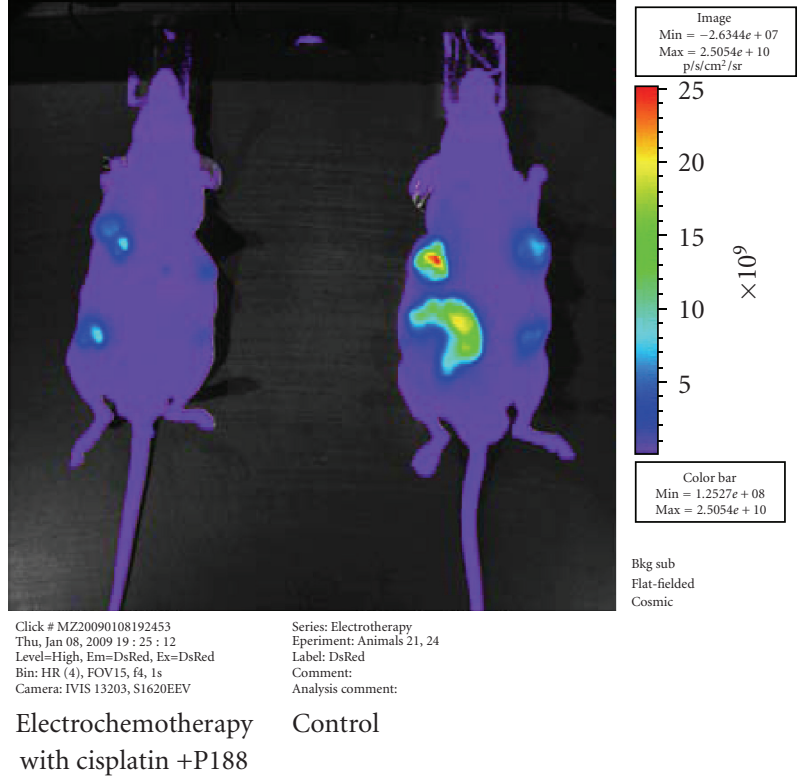

(Ds red labeling)

(a)

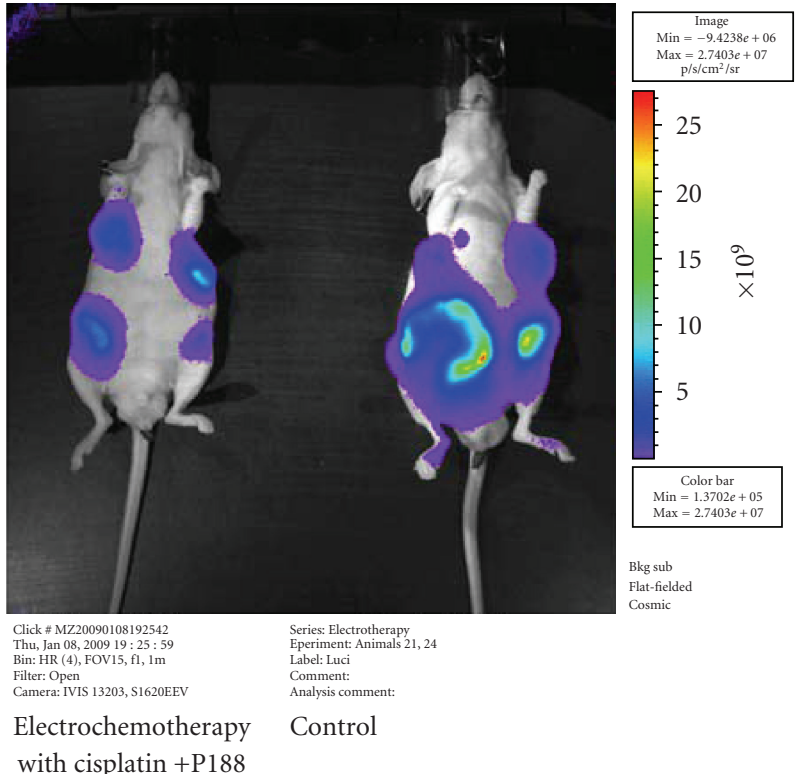

(Luciferin-luciferase labeling)

(b)

Figure 8: Visualisation of the HeLa tumors by (a) red fluorescence protein-Ds red and (b) luciferase/luciferin reaction by using an IVIS 100 system at 30 days after the first electrotreatment.

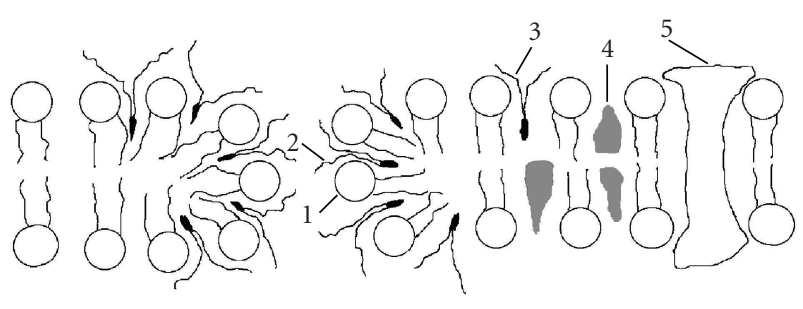

1- Phospholipids in pore

2- P188 in pore (black part is the hydrophobic section of P188)

3- P188 in membrane defect

4- Cholesterol

5- Integrated membrane protein

FIGURE 9: Scheme on the mechanism of P188 interaction in biological membrane (explanation is given in the text).

we have shown that anticancer drugs can penetrate into the electroporated cells in the presence of P188. Nude mice are suitable animals for implanting human tumors but this is due to their weak and delayed immune response. For this reason the model used cannot predict the influence of P188 on inflammatory processes such as secondary injury effects and the application of P188 in the human tumor electrochemotherapy.

Electrochemotherapy is used as a method for treating human and animals tumors $[8,10-21]$. The use of P188 for pet cancer patients with spontaneous tumors is under studies (Spugnini, E. and Tsoneva, I. unpublished data). The use of P188 to reduce the inflammatory response of the electrochemotherapy could be translated to humans.

\section{Acknowledgments}

The authors gratefully acknowledge for the support from The Bulgarian National Fund (Grant D0 02/178) and partly from DFG grant to I. Tsoneva

\section{References}

[1] G. Saulis, "The loading of human erythrocytes with small molecules by electroporation," Cellular and Molecular Biology Letters, vol. 10, no. 1, pp. 23-35, 2005.

[2] O. Tounekti, G. Pron, J. Belehradek Jr., and L. M. Mir, "Bleomycin, an apoptosis-mimetic drug that induces two types of cell death depending on the number of molecules internalized," Cancer Research, vol. 53, no. 22, pp. 5462-5469, 1993.

[3] M. J. Jaroszeski, V. Dang, C. Pottinger, J. Hickey, R. Gilbert, and R. Heller, "Toxicity of anticancer agents mediated by electroporation in vitro," Anti-Cancer Drugs, vol. 11, no. 3, pp. 201-208, 2000.

[4] I. Tsoneva, B. Nikolova, M. Georgieva et al., "Induction of apoptosis by electrotransfer of positively charged proteins as Cytochrome C and histone H1 into cells," Biochimica et Biophysica Acta, vol. 1721, no. 1-3, pp. 55-64, 2005.

[5] E. Neumann, S. Kakorin, I. Tsoneva, B. Nikolova, and T. Tomov, "Calcium-mediated DNA adsorption to yeast cells and kinetics of cell transformation by electroporation," Biophysical Journal, vol. 71, no. 2, pp. 868-877, 1996.

[6] L. M. Mir, L. F. Glass, G. Sersa et al., "Effective treatment of cutaneous and subcutaneous malignant tumours by electrochemotherapy," British Journal of Cancer, vol. 77, no. 12, pp. 2336-2342, 1998. 
[7] G. Serša, B. Štabuc, M. Čemažar, D. Miklavčičc, and Z. Rudolf, "Electrochemotherapy with cisplatin: the systemic antitumour effectiveness of cisplatin can be potentiated locally by the application of electric pulses in the treatment of malignant melanoma skin metastases," Melanoma Research, vol. 10, no. 4, pp. 381-385, 2000.

[8] E. Peycheva, I. Daskalov, and I. Tsoneva, "Electrochemotherapy of Mycosis fungoides by interferon- $\alpha$," Bioelectrochemistry, vol. 70, no. 2, pp. 283-286, 2007.

[9] L. Heller, K. Merkler, J. Westover et al., "Evaluation of toxicity following electrically mediated interleukin-12 gene delivery in a B16 mouse melanoma model," Clinical Cancer Research, vol. 12, no. 10, pp. 3177-3183, 2006.

[10] R. Zhou, J. E. Norton, N. Zhang, and D. A. Dean, "Electroporation-mediated transfer of plasmids to the lung results in reduced TLR9 signaling and inflammation," Gene Therapy, vol. 14, no. 9, pp. 775-780, 2007.

[11] E. P. Spugnini and A. Porrello, "Potentiation of chemotherapy in companion animals with spontaneous large neoplasm by application of bipolar electric pulse," Journal of Experimental and Clinical Cancer Research, vol. 22, no. 4, pp. 571-580, 2003.

[12] E. P. Spugnini, G. Citro, and A. Porrello, "Rational design of new electrodes for electrochemotherapy," Journal of Experimental and Clinical Cancer Research, vol. 24, no. 2, pp. 245254, 2005.

[13] E. P. Spugnini, E. Dragonetti, B. Vincenzi, N. Onori, G. Citro, and A. Baldi, "Pulse-mediated chemotherapy enhances local control and survival in a spontaneous canine model of primary mucosal melanoma," Melanoma Research, vol. 16, no. 1, pp. 23-27, 2006.

[14] E. P. Spugnini, A. Baldi, B. Vincenzi et al., "Intraoperative versus postoperative electrochemotherapy in high grade soft tissue sarcomas: a preliminary study in a spontaneous feline model," Cancer Chemotherapy and Pharmacology, vol. 59, no. 3, pp. 375-381, 2007.

[15] E. P. Spugnini, B. Vincenzi, F. Baldi, G. Citro, and A. Baldi, "Adjuvant electrochemotherapy for the treatment of incompletely resected canine mast cell tumors," Anticancer Research, vol. 26, no. 6B, pp. 4585-4589, 2006.

[16] E. P. Spugnini, G. Citro, A. D’Avino, and A. Baldi, "Potential role of electrochemotherapy for the treatment of soft tissue sarcoma: first insights from preclinical studies in animals," International Journal of Biochemistry and Cell Biology, vol. 40, no. 2, pp. 159-163, 2008.

[17] E. P. Spugnini, G. Citro, P. Mellone, I. Dotsinsky, N. Mudrov, and A. Baldi, "Electrochemotherapy for localized lymphoma: a preliminary study in companion animals," Journal of Experimental and Clinical Cancer Research, vol. 26, no. 3, pp. 343 346, 2007.

[18] E. P. Spugnini, F. Baldi, P. Mellone et al., "Patterns of tumor response in canine and feline cancer patients treated with electrochemotherapy: preclinical data for the standardization of this treatment in pets and humans," Journal of Translational Medicine, vol. 5, pp. 48-52, 2007.

[19] D. M. Soden, J. O. Larkin, C. G. Collins et al., "Successful application of targeted electrochemotherapy using novel flexible electrodes and low dose bleomycin to solid tumours," Cancer Letters, vol. 232, no. 2, pp. 300-310, 2006.

[20] L. F. Glass, M. Jaroszeski, R. Gilbert, D. S. Reintgen, and R. Heller, "Intralesional bleomycin-mediated electrochemotherapy in 20 patients with basal cell carcinoma," Journal of the American Academy of Dermatology, vol. 37, no. 4, pp. 596-599, 1997.
[21] M. Rebersek, T. Cufer, M. Cemazar, S. Kranjc, and G. Sersa, "Electrochemotherapy with cisplatin of cutaneous tumor lesions in breast cancer," Anti-Cancer Drugs, vol. 15, no. 6, pp. 593-597, 2004.

[22] J. D. Marks, W. Cromie, and R. Lee, "Nonionic surfactant prevent NMDA-induced death in cultured hippocampal neurons," Society for Neuroscience Abstracts, vol. 24, no. 1, p. 462, 1998.

[23] F. A. Merchant, W. H. Holmes, M. Capelli-Schellpfeffer, R. C. Lee, and M. Toner, "Poloxamer 188 enhances functional recovery of lethally heat-shocked fibroblasts," Journal of Surgical Research, vol. 74, no. 2, pp. 131-140, 1998.

[24] R. C. Lee, L. P. River, F.-S. Pan, L. Ji, and R. L. Wollmann, "Surfactant-induced sealing of electropermeabilized skeletal muscle membranes in vivo," Proceedings of the National Academy of Sciences of the United States of America, vol. 89, no. 10, pp. 4524-4528, 1992.

[25] J. D. Marks, C. Y. Pan, T. Bushell, W. Cromie, and R. C. Lee, "Amphiphilic, tri-block copolymers provide potent membrane-targeted neuroprotection," The FASEB Journal, vol. 15, no. 6, pp. 1107-1109, 2001.

[26] P. Liu-Snyder, M. P. Logan, R. Shi, D. T. Smith, and R. B. Borgens, "Neuroprotection from secondary injury by polyethylene glycol requires its internalization," Journal of Experimental Biology, vol. 210, no. 8, pp. 1455-1462, 2007.

[27] A. Jordanova, Surface properties and behavior of lipid liquid crystal faces, Ph.D. thesis, Sofia, Bulgaria, 2006.

[28] S. A. Maskarinec, G. Wu, and K. Y. Lee, "Membrane sealing by polymers," Annals of the New York Academy of Sciences, vol. 1066, pp. 310-320, 2005.

[29] T. Mosmann, "Rapid colorimetric assay for cellular growth and survival: application to proliferation and cytotoxicity assays," Journal of Immunological Methods, vol. 65, no. 1-2, pp. 55-63, 1983.

[30] S. M. Konstantinov, H. Eibl, and M. R. Berger, "Alkylphosphocholines induce apoptosis in HL-60 and U-937 leukemic cells," Cancer Chemotherapy and Pharmacology, vol. 41, no. 3, pp. 210-216, 1998.

[31] G. Pucihar, T. Kotnik, J. Teissié, and D. Miklavčič, "Electropermeabilization of dense cell suspensions," European Biophysics Journal, vol. 36, no. 3, pp. 173-185, 2007.

[32] T. C. Tomov, "Quantitative dependence of electroporation on the pulse parameters," Bioelectrochemistry and Bioenergetics, vol. 37, no. 2, pp. 101-107, 1995.

[33] J. M. Collins, F. Despa, and R. C. Lee, "Structural and functional recovery of electropermeabilized skeletal muscle in-vivo after treatment with surfactant poloxamer 188," Biochimica et Biophysica Acta, vol. 1768, no. 5, pp. 1238-1246, 2007.

[34] I. Daskalov, N. Mudrov, and E. Peycheva, "Exploring new instrumentation parameters for electrochemotherapy: attacking tumors with bursts of biphasic pulses instead of single pulses," IEEE Engineering in Medicine and Biology Magazine, vol. 18, no. 1, pp. 62-66, 1999.

[35] A. V. Kabanov, I. R. Nazarova, I. V. Astafieva et al., "Micelle formation and solubilization of fluorescent probes in poly(oxyethylene- $b$-oxypropylene- $b$-oxyethylene) solutions," Macromolecules, vol. 28, no. 7, pp. 2303-2314, 1995.

[36] P. Alexandridis and T. A. Hatton, "Poly(ethylene oxide)poly(propylene oxide)poly(ethylene oxide) block copolymer surfactants in aqueous solutions and at interfaces: thermodynamics, structure, dynamics, and modeling," Colloids and Surfaces A, vol. 96, no. 1-2, pp. 1-46, 1995. 
[37] P. J. Photos, H. Bermudez, H. Aranda-Espinoza, J. Shillcock, and D. E. Discher, "Nuclear pores and membrane holes: generic models for confined chains and entropic barriers in pore stabilization," Soft Matter, vol. 3, no. 3, pp. 364-371, 2007.

[38] D. J. Curry, D. A. Wright, R. C. Lee, U. J. Kang, and D. M. Frim, "Surfactant poloxamer 188-related decreases in inflammation and tissue damage after experimental brain injury in rats," Journal of Neurosurgery, vol. 101, no. 1, supplement, pp. 9196, 2004. 

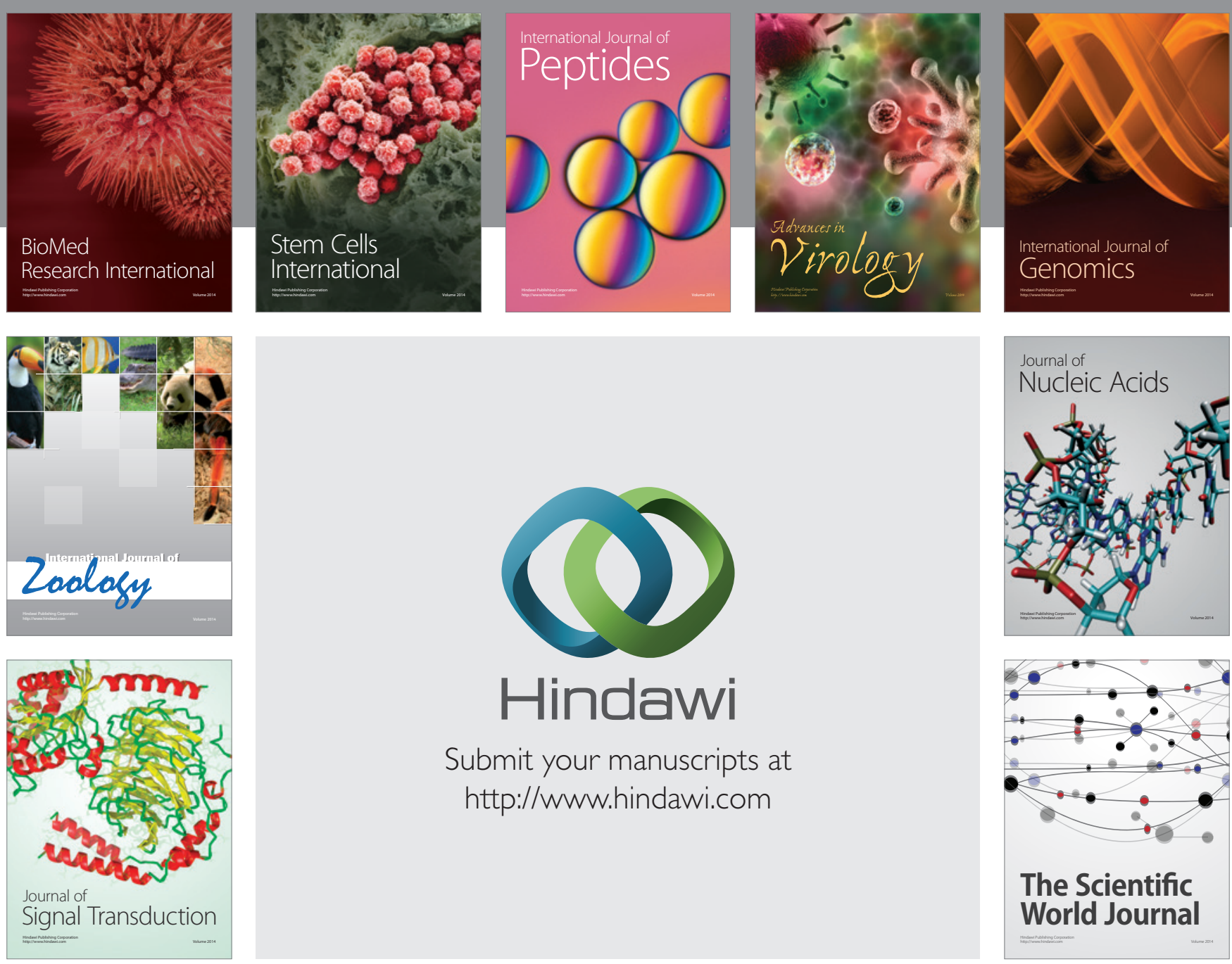

Submit your manuscripts at

http://www.hindawi.com
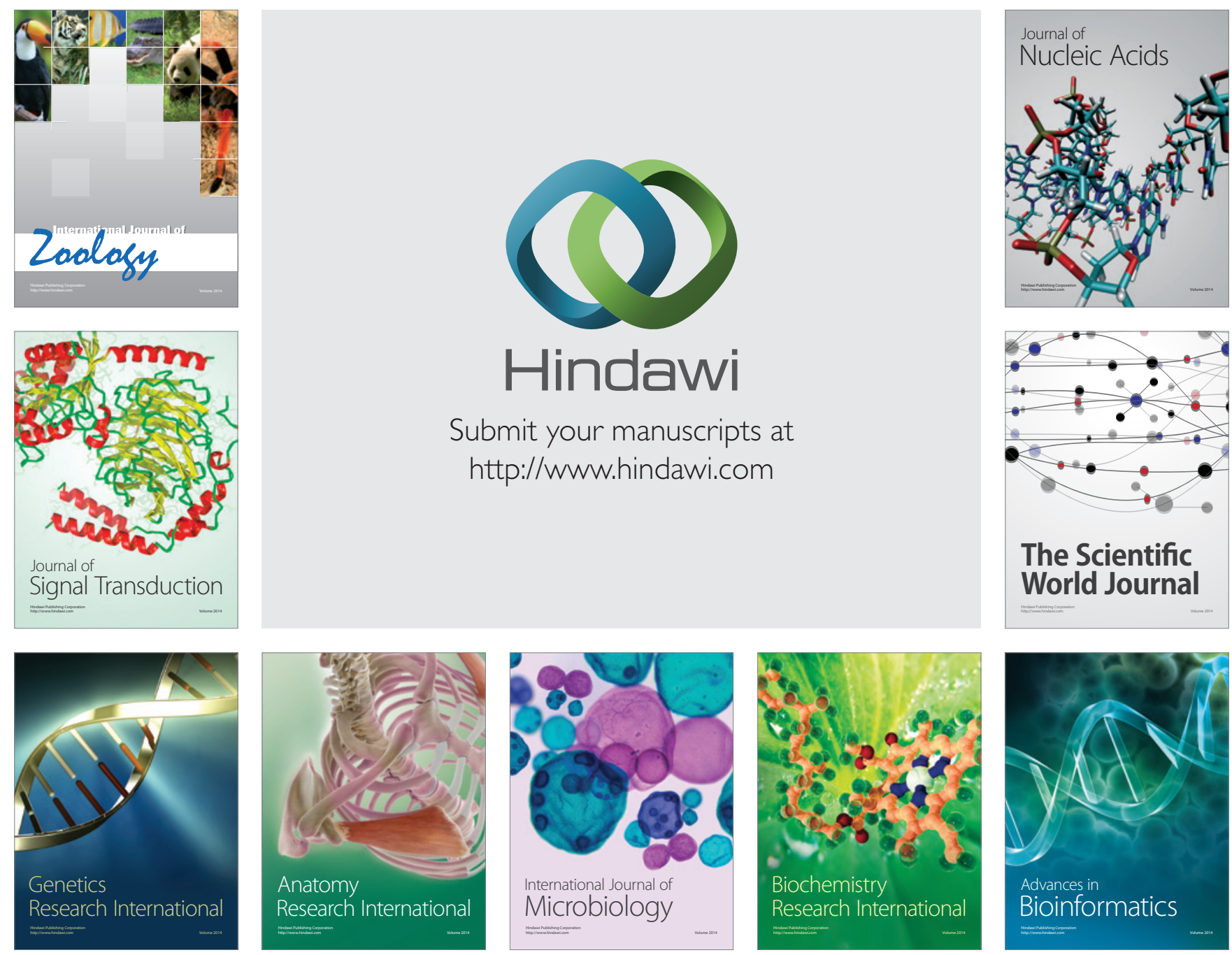

The Scientific World Journal
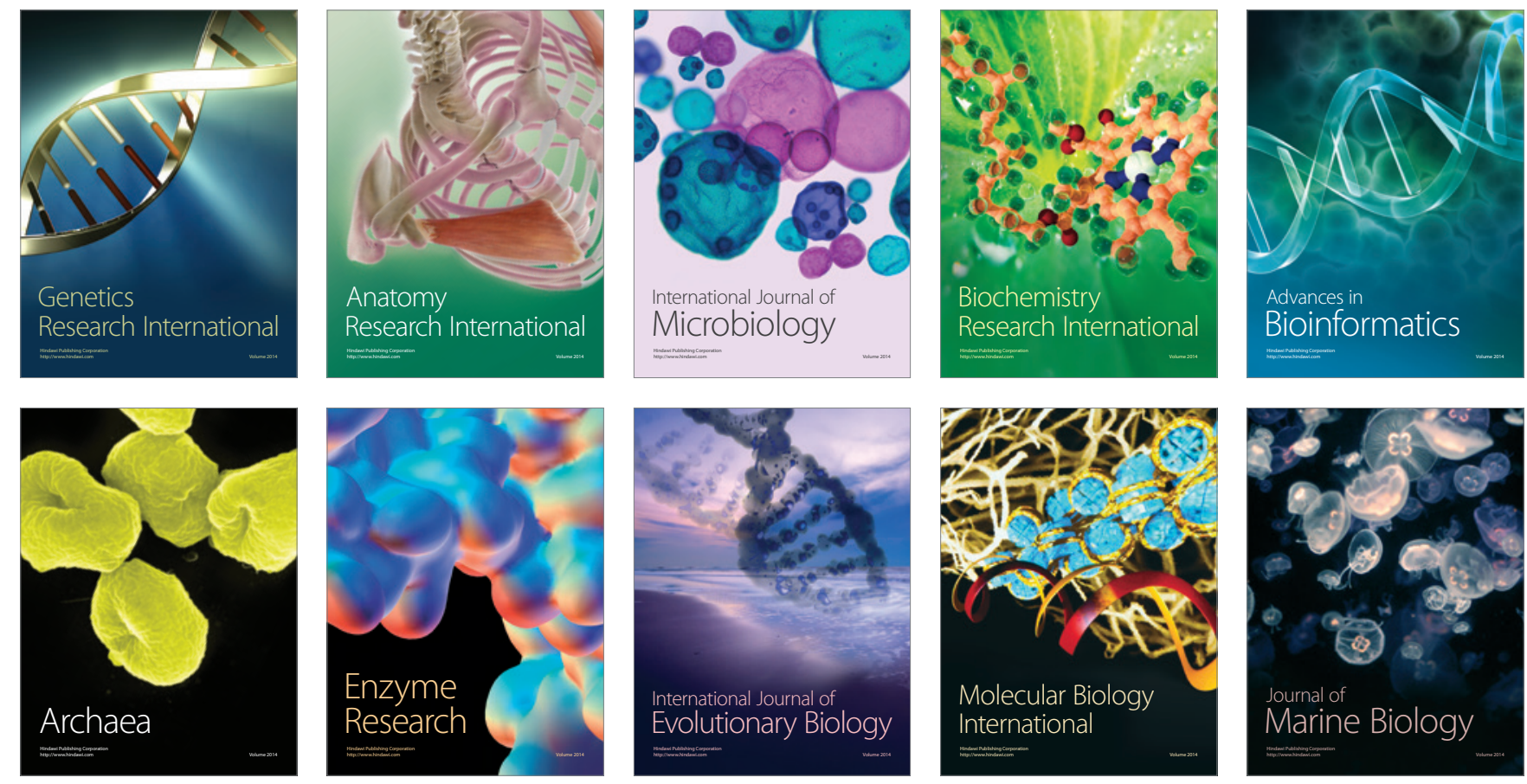